\title{
Study on the effect of smoking on Type 2 Diabetic Patients in Federal Medical Center Owerri, Southeastern Nigeria
}

\author{
Nwaokoro Joakin Chidozie ${ }^{1}$, Ede Alison Okorie ${ }^{1}$, O. Emerole Chima ${ }^{1}$, N.O. Ibe Sally ${ }^{1}$, A.N. Amadi', \\ I.N.S. Dozie', S.C. Iwuji ${ }^{2}$, A.A. Nwaokoro ${ }^{3}$ \\ ${ }^{1}$ Department of Public Health Technology, School of Health Technology; Federal University of Technology Owerri, Imo State, Nigeria, \\ ${ }^{2}$ Department of Biomedical Technology, Federal University of Technology Owerri, Imo State, Nigeria, ${ }^{3}$ Department of Servicom Unit, Federal \\ University of Technology Owerri, Imo State, Nigeria.
}

\section{A B S TR A C T}

Background: Diabetes is an umbrella term for a number of metabolic diseases that affects the body's ability to control blood glucose levels. The hormone insulin is produced in the pancreas, and helps to metabolize glucose for energy. Diabetes occurs when insulin production is impaired. Objective: The present study was to examine the effect of smoking on type 2 diabetic patients visiting Federal Medical Centre. Materials and Methods: The sample size was 97 respondents while the major instrument for data collection was a well constructed, validated and reliably tested questionnaire, including observations made on secondary existing record data of the hospital. Data obtained was analyzed using frequency distribution, means, standard deviation and fisher's exact test. Results: Results of the study indicated that majority of the diabetic patients $78(80.4 \%)$ were non smokers, while $8(8.2 \%)$ and $11(11.3 \%)$ respondents were current and past smokers respectively. Maintainance of good glycaemic control should be considered as the therapeutic goal for prevention of diabetic complications. Conclusion: A comprehensive programmes should be initiated to prevent smoking in type 2 diabetic patients such as: regular physical activity, health education on diabetes, smoking cessation, home blood sugar monitoring - minimize smoking impact to body organs that may lead to many complications.

Key words: Smoking, Diabetes, Glycaemic, Hyperglycaemia and Hypoglycaemia

\section{INTRODUCTION}

Diabetes exerts a considerable impact on the economies and health resources of any nation. The impact of diabetes on individual lives have subdued hopes and vigor to pursue meaningful goals in life. As a chronic condition, it places immense burden and untold hardship to people with diabetes and families. When insulin production in the body is diminished or insufficient, it leads to a state know as hyperglycaemia. ${ }^{1}$ However, if hyperglycaemia is left untreated it can become severe and leads to serious complications requiring emergency care, such as diabetes coma. ${ }^{2}$ Insulin is a hormone made by the pancreas that helps the body store and use insulin. ${ }^{3}$ Therefore, lack of insulin in the body is the hallmark of diabetes complications. ${ }^{4}$

\section{HYPERGLYCAEMIA}

Hyperglycemia is when an excessive amount of glucose circulates in the blood plasma and is above $126 \mathrm{mg} /$ $\mathrm{dl}$ or $7 \mathrm{mmol} / \mathrm{L} .{ }^{4}$ It could be due to excessive intake of carbohydrate diet, lack of physical activity and defect in insulin response to high blood sugar. ${ }^{5}$ When blood passes through the filtering system in the kidney, glucose is normally retained but when the blood glucose level rises above normal, it 'spills over' into the urine. ${ }^{6}$ This makes the urine so concentrated thereby passing out more water than normal. People with high blood glucose therefore produce large volumes of urine and become dehydrated and very thirsty. ${ }^{4}$ When the blood glucose rises in the absence of insulin in a patient, cells turn to fats. Burning

Address for Correspondence:

Nwaokoro Joakin Chidozie, Department of Public Health Technology, School of Health Technology; Federal University of Technology

Owerri, Imo State, Nigeria. P.M.B 1526.

E-mail: ashim126@gmail.com; Phone: 09914208139.

(C) Copyright AJMS 
fats in the body yield chemicals known as ketones. If these are produced faster than they can be disposed of by the body, they build up in the bloodstream and become toxic. Ketone bodies decrease the $\mathrm{pH}$ of the blood and thus causing lungs to hyperventilate. This life-threatening state is called as ketoacidosis which is associated with type I diabetes. Prolonged severe high blood glucose levels in people with type 2 diabetes may lead to a condition known as 'Hyperosmolar Non-Ketotic Coma' (HONK) which is caused by extreme loss of fluid (dehydration) and the resulting chemical imbalance in the blood. ${ }^{7}$ Hyperglycemia is less of an immediate threat to the patient, compared with hypoglycemia but in the long term it can add to the risk of developing diabetic complications such as loss of sight, kidney failure, nerve damage and heart disease. ${ }^{2}$

\section{HYPOGLYCAEMIA}

Hypoglycemia can occur as a result of consuming less carbohydrates, exercising more than usual, insulin in the body having a greater effect than normal when the blood glucose falls, cells in the body are starved of glucose. ${ }^{2}$ Cells in the brain and nervous system suffer. Early signs include sweating, shaking, hunger and dizziness. If not treated immediately, the person can suffer from convulsions, and may progress into a state of unconsciousness. Treatment of a hypoglycemic attack or 'hypo' is glucose - sugar in its most simple form. If the person is unconscious then they may require an injection of glucagon, a substance which tells the liver to release glucose into the bloodstream. ${ }^{4}$

\section{TYPE 2 DIABETES}

Type 2 diabetes, is likely to occur in adulthood and is caused by lowered effectiveness of insulin. This is the most common form of diabetes, accounting for up to $90 \%$ of incidence in the population. ${ }^{5}$ When Type 2 diabetes developed, the body can still produce insulin, but not sufficient enough to performed its work properly. This type of diabetes usually develops gradually after the age of 40 , though in South Asian and African-Caribbean people, it often appears after the age of 25. (ibid) Type 2 diabetes is also called Non-Insulin Dependent Diabetes and it is more common, less severe than Type 1 diabetes. ${ }^{6}$ Type 2 diabetes differs from type 1 diabetes because of the body's inability to produce insulin, while type 2 diabetes is the body's inability to make use of insulin produced by the body.

The reason is that insufficient insulin is produced to cope with the body's requirement and to convert glucose into energy is not impaired in type $2 .{ }^{8}$ Type 2 diabetes usually starts with cells that are resistant to insulin, that means they are unable to take in insulin as it moves glucose from the blood into cells. With insulin resistance, the pancreas has to over work to produce enough insulin so that cells can get the energy they need and it involves a complex process that eventually leads to type 2 diabetes. In type 2 diabetes, the beta cells do not respond properly to the blood glucose level, and insulin secretion is not sufficient to keep blood glucose levels within normal limits'. The first enzyme to react with the glucose as it enters the cell is called glucokinase and a genetic defect in this molecule was classified as responsible for many cases of Mature Onset Diabetes of the young (MODY). ${ }^{9}$

According to,${ }^{10}$ Type 2 Diabetes is the most common form of diabetes accounting for about 90 to 95 percent of all diagnosed cases of diabetes. Over 100 million people worldwide have type 2 diabetes and the prevalence is increasing dramatically in both developed and developing countries including Nigeria. ${ }^{10}$

\section{RISK FACTORS OF TYPE 2 DIABETES}

Genetic and environmental factors contribute to the development of diabetes but the development of type 2 diabetes is more likely to occur if the following factors are also present: physical inactivity, being overweight, family history of Type 2 diabetes, previous diabetes in pregnancy. ${ }^{4}$ According to, ${ }^{5}$ Being overweight, having high blood pressure, having high blood cholesterol levels, eating an unbalanced diet, smoking and physical inactivity are major risk factors for developing Type 2 diabetes which is life-threatening in its own right.

\section{CONCEPT OF SMOKING}

Smoking is the inhalation of the smoke of burning tobacco encased in cigarettes, pipes, and cigars. Casual smoking is the act of smoking only occasionally, usually in a social situation or to relieve stress. A smoking habit is a physical addiction to tobacco products. Many health experts now regard habitual smoking as a psychological addiction and one with serious health consequences. No one starts smoking to become addicted to nicotine. It isn't known how much nicotine may be consumed before the body becomes addicted. Once smoking becomes a habit, the smoker faces a lifetime of health risks associated with one of the strongest addictions known to man. It is thought that some genetic variations affect the speed of nicotine metabolism in the body and the activity level of nicotinic receptors in the brain. Tobacco smoke contains over 4,000 chemicals and more than 200 of these chemicals are known be toxic and capable of causing cancer in people. ${ }^{11}$ Nicotine and carbon monoxide in tobacco smoke are most strongly implicated in the processes 
leading to development of cardiovascular disease but other chemicals may also be involved. ${ }^{11}$ According to, ${ }^{12}$ Smoking is the leading cause of avoidable death globally. Smoking is recognized as the leading preventable cause of death, or contributing to the deaths of approximately 430,700 Americans each year. Studies showed that 70\% of smokers in the United States would like to quit; in any given year, however, only about $3.6 \%$ of the country's 47 million smokers quit successfully. ${ }^{11,12}$ Due to smoking effect, every year about 4 million people die because of smoking and it is estimated that tobacco causes about $8.8 \%$ of deaths worldwide. Smoking is a well-known risk factor for coronary heart disease which is caused by vascular disability via its pathological change such as arteriosclerosis through the mechanisms of inflammation and endothelial dysfunctions. ${ }^{13}$ Cigarette smoking is well established as a causal factor in coronary heart disease such as heart attack, high blood pressure, stroke and it has an increased chance of lung cancer, cervical cancer and respiratory diseases such as emphysema, asthma, and chronic bronchitis. ${ }^{14}$ Smoking is associated with increased risk and enhances progression of chronic diabetes related complications like nephropathy and retinopathy. ${ }^{15}$ Smoking affects the health of smokers and non-smokers at the same time when exposed. ${ }^{16,17}$

\section{REASONS WHY DIABETIC PEOPLE SMOKE}

According to a research done by, ${ }^{18}$ People smoke for different reasons as follows: To cope with depression, make them feel they have more energy, help to make a person feel more at ease, bring joy at the time of smoking, Diabetic patients view smoking as a strategy for controlling their weight and weight loss.

\section{EFFECT OF SMOKING ON HEALTH}

Smoking has effect on a person's health in so many ways which include the following: Smoking causes coronary heart disease, abdominal aortic aneurysm; lung, mouth and throat cancer; nerve and blood vessel damage. Cigarette smoking causes reduced circulation by narrowing the blood vessels. Smokers have a lower survival rate after surgery compared to that of non-smokers because of damage to the body's host defenses, delayed wound healing, and reduced immune response and this is aggravated with diabetes. There is no low risk level of smoking. ${ }^{8}$ Each cigarette one smokes is capable of causing damage in the body. Toxic substances from cigarette smoke circulate in the bloodstream, interfering with the efficient working of the endothelium, and causing the development of atherosclerotic lesions in the arterial walls. ${ }^{19}$ These collections narrow the arteries, slowly impairing blood flow, and making the arteries harder, less elastic, and more liable to rupture. Smoking also has a direct effect on platelets, leading to increased activation and stickiness. ${ }^{11}$ It causes an increased risk of thrombosis or development of blood clots.

The 2004 report of the US Surgeon General published the following four major conclusions about the health consequences of Smoking. ${ }^{11}$

- Smoking harms nearly every organ of the body, causing many diseases and reducing the health of smokers in general.

- Quitting smoking has immediate as well as long-term benefits, reducing risks for diseases caused by smoking and improving health in general.

- Smoking cigarettes with lower machine-measured yields of tar and nicotine provides no clear benefit to health.

\section{EFFECT OF SMOKING ON WOMEN}

Women who smoke experience a low rate of fertility and are twice infertile as non-smokers. Low fertility is evident both in female smokers who have never been pregnant (primary infertility) and those who have had one or more prior pregnancies (secondary infertility). ${ }^{11}$ Female smokers are less likely to respond to infertility treatments such as invitro fertilization (IVF), showing lower rates for successful fertilization, implantation and ongoing pregnancy. ${ }^{20} \mathrm{~A}$ woman that smokes is likely to have shorter menstrual cycles and have higher risk of not ovulating regularly, which may also reduce fertility. ${ }^{21}$

\section{Smoking and pregnancy}

Smoking has a range of adverse effects on both mother and unborn baby during pregnancy. ${ }^{20}$ Pregnant women who smoke may also be at an increased risk of developing gestational diabetes. Maternal smoking during pregnancy causes reduced lung function in infants, and may also cause an increase in the number of lower respiratory tract infections during infancy. ${ }^{20}$ The effects of maternal smoking in uterus may also be related to an increased risk of having impaired lung function in childhood and adulthood. ${ }^{11}$ Tobacco smoke appears to have a direct negative effect on milk quality and quantity produced. ${ }^{11}$ It is thought that nicotine may affect the activity of prolactin, a hormone essential for milk production. ${ }^{20}$ Smoking has a negative impact on the health of both the mother and the unborn child, because oxygen supply to the baby is compromised due to oxygen-reducing effects of carbon monoxide in cigarette smoke. ${ }^{20}$ Nicotine is found in foetal blood, amniotic fluid and breast milk had a direct effect on foetal heartbeat and breathing movements. ${ }^{22}$ Smoking affects the healthy development and function of the umbilical cord and placenta, and causes abnormalities or insufficiencies 
that can lead to serious complications for the success of the pregnancy and the safe delivery of the baby. ${ }^{11}$

\section{EFFECT OF SMOKING ON MEN}

\section{Sperm production}

Smoking may be associated with a lower sperm count and volume, and an increased likelihood of sperm abnormality. ${ }^{23}$ This is worst on people with diabetes because diabetes affects sperm production leading to impotence or erectile dysfunction.

\section{Erectile dysfunction}

Erectile dysfunction is the persistent inability to attain and maintain penile erection adequate for satisfactory sexual performance. ${ }^{24}$ Smoking is a risk factor for erectile dysfunction. ${ }^{25}$ Smokers of up to 20 cigarettes a day are $24 \%$ more likely to experience erectile problems, and heavier smokers are $40 \%$ more likely to have erectile difficulties than non-smokers. ${ }^{24}$ Males with diabetes who smoke have increased risk of impotence.

\section{PASSIVE SMOKING}

Secondhand smoke is the term used to describe the ambient smoke that is a by-product of active smoking. ${ }^{26}$ It consists of smoke that has been exhaled by the smoker and smoke drifting from the smouldering tip of the cigarette. Smokers generally take only several puffs from a cigarette which may burn for some minutes, smaller amounts of smoke also reach the environment by diffusion through the cigarette paper, and from the mouthpiece of the cigarette. Since most tobacco is smoked in the form of cigarettes, cigarettes are the major source of secondhand smoke. ${ }^{11}$

Secondhand smoke can be detected in the indoor environment and changes in nature with particles coagulating, expanding, condensing or evaporating, depending on concentration, ventilation, humidity, sunlight and other conditions. ${ }^{27}$ Some compounds, such as nicotine and some polycyclic aromatic hydrocarbons exist in both the gaseous and the particulate phase of secondhand smoke. ${ }^{28}$ Individuals with existing diabetes are at greater risk of developing coronary heart disease if exposed to secondhand smoke. There is early research suggesting that the risk of developing glucose intolerance is increased in adults exposed to secondhand smoke over a 15 -year period. ${ }^{29}$

\section{CONSEQUENCES OF SMOKING ON PEOPLE WITH TYPE 2 DIABETES}

People with diabetes may have an increased risk of heart disease, which is further elevated if they smoke. Type 2 diabetes acts in several ways to damage the heart; high glucose levels affect the walls of the arteries making them more likely to develop fatty deposits which in turn make it more difficult for the blood to circulate. People with type 2 diabetes are more likely to have high blood pressure, high levels of fats such as triglycerides and also more likely to have lower levels of the protective HDL cholesterol. ${ }^{29}$ Based on the study carried out by, ${ }^{30}$ to evaluate the relations among smoking, body weight, body fat distribution, the following findings were made; In the short term, nicotine increases energy expenditure and could reduce appetite, which may explain why smokers tend to have lower body weight than non-smokers and why smoking cessation is frequently followed by weight gain. In contrast, heavy smokers tend to have greater body weight than light smokers or nonsmokers. The study concludes that smoking increases insulin resistance and is associated with central fat accumulation. ${ }^{30}$ Smokers with Type 2 diabetes are at increased risk of illness and premature death, mostly through development of cardiovascular disease, but other disease processes associated with diabetes may also be made worse by smoking. Also, smokers with Type 2 diabetes are more likely to increase their risk of coronary heart disease, stroke and peripheral vascular disease. Some primary studies have assessed the association between smoking and incidence of glucose abnormalities, suggesting that active smoking could be independently associated with glucose intolerance, impaired fasting glucose, and type 2 diabetes. Smoking may be a modifiable risk factor for type 2 diabetes. ${ }^{12}$ There is no safe level of smoking and there are absolutely no health benefits. The effects of smoking on the blood vessels of the body, inflammation, and other possible factors may also contribute to the very serious negative consequences of cigarette smoking for people with type 2 diabetes.

\section{MATERIALS AND METHODS}

A hospital-based cross-sectional survey design was used for this research to enhance the achievement of the study objectives. This study which was carried out among 97 diabetic patients to ascertain the effect of smoking in type 2 diabetes patients visiting Federal Medical Centre (FMC), Owerri Southeastern, Nigeria. Ethical approval was obtained from the ethical committee of the Federal Medical centre in Owerri after which an advocacy visits were paid to the various departments and units. The study population involved in the research is all the diabetic patients visiting the hospital in the study area and this formed the sample frame. The inclusion criteria are those with type 2 diabetes of age 35-75 and exclusion of those with age below 35 , type 1 diabetes, and gestational diabetes. The sample of the study consists of one hundred Type 2 diabetic patients visiting FMC. The study instrument was a 
well structured questionnaire classified into three sections: socio-demographic characteristics of the respondent such as age, gender, educational status, marital status, and occupation; physical activity and knowledge on effect of smoking on type 2 diabetes in relation to body mass index (BMI), blood glucose level and blood pressure of the respondents. The data collection was self-administered questionnaires by the researcher and a secondary data were collected from existing records of the hospital. The validity/reliability of the instrument was ascertained by health experts on diabetes prevention and control who criticized and made possible corrections relevant to the objectives of the study. Data was collected with the use of pre-tested semi structured questionnaire and observational checklist in the hospital. The data collected were edited and coded into the computer for analysis using the statistical package for social sciences (SPSS) Version 20.0. Tables were used to present frequency distribution for the effect of smoking on diabetic patients and level of statistical significance was set at $\mathrm{p}$-value of $<0.05$.

\section{RESULTS}

Out of the 100 copies of questionnaire distributed, 97 copies were returned with rate of $97 \%$. Data was expressed as means \pm standard deviation. The results shown in Table 1 are the socio-demographic characteristics of the respondents. The survey sample included 97 respondents drawn from only type 2 diabetic patients comprising

\begin{tabular}{|c|c|c|c|}
\hline Variables & Responses & $\begin{array}{l}\text { Frequency } \\
\text { (N) }\end{array}$ & $\begin{array}{c}\text { Percentage } \\
(\%)\end{array}$ \\
\hline \multirow{6}{*}{$\begin{array}{l}\text { Age of } \\
\text { participants } \\
\text { of the } \\
\text { respondents }\end{array}$} & $35-44$ & 9 & 9.3 \\
\hline & $45-54$ & 26 & 26.8 \\
\hline & $55-64$ & 18 & 18.6 \\
\hline & $65-74$ & 27 & 27.8 \\
\hline & $75+$ & 17 & 17.5 \\
\hline & Total & 97 & 100 \\
\hline \multirow[t]{3}{*}{ Gender } & Male & 61 & 62.9 \\
\hline & Female & 36 & 37.1 \\
\hline & Total & 97 & 100 \\
\hline \multirow{5}{*}{$\begin{array}{l}\text { Marital } \\
\text { status of the } \\
\text { respondents }\end{array}$} & Married & 55 & 56.7 \\
\hline & Single & 1 & 1.0 \\
\hline & Divorced & 9 & 9.3 \\
\hline & Widowed & 32 & 33.0 \\
\hline & Total & 97 & 100 \\
\hline \multirow{5}{*}{$\begin{array}{l}\text { Educational } \\
\text { status of the } \\
\text { respondents }\end{array}$} & Primary education & 15 & 15.5 \\
\hline & Secondary education & 28 & 28.9 \\
\hline & Tertiary education & 49 & 50.5 \\
\hline & None & 5 & 5.2 \\
\hline & Total & 97 & 100 \\
\hline \multirow{5}{*}{$\begin{array}{l}\text { Occupation } \\
\text { of the } \\
\text { respondents }\end{array}$} & Civil servant & 49 & 50.5 \\
\hline & Trader & 16 & 16.5 \\
\hline & Farmer & 11 & 11.3 \\
\hline & Others & 21 & 21.6 \\
\hline & Total & 97 & 100 \\
\hline
\end{tabular}

$61(62.9 \%)$ males and 36(37.1\%) females. The mean age of respondents was $61.47 \pm 12.7$ years with their age range between 35 and $\geq 75$ years. Patients between the age of 35 and 44 years were $9(9.3 \%), 26(26.8 \%)$ were between 45 and 54 years, $18(18.6 \%)$ falls between 55 and 64 years, $27(27.8 \%)$ were between the age of 65 and 74 compared to $17(17.5 \%)$ of the patients that are $\geq 75$ years of age. The distribution of respondents according to their marital status is shown in Table 1. Majority of them 55(56.7\%) were married; $1(1.0 \%)$ was single; $9(9.3 \%)$ were divorced while $32(33.0 \%)$ were widows/widowers. Table 1 also presents the distribution of the sample according to the level of education attained. There were differences in the educational attainment between respondents. 15(15.5\%) had primary education; $28(28.9 \%)$ attended secondary school; 49(50.5\%) obtained tertiary education while 5(5.2\%) did not obtain any formal education. The occupational distribution among the participants is presented in Table 1. Among those interviewed, $49(50.5 \%)$ were civil servants; $16(16.5 \%)$ were traders; $11(11.3 \%)$ were farmers while $21(21.6 \%)$ had other forms of occupation.

The results in Table 2 showed information on physical activity practice of the patients. Out of 97 interviewed, $42(43.3 \%)$ reported that they practice physical activity while $52(53.6 \%)$ do not. Others like 3(3.1\%) patients were not certain if they practice any form of physical activity or not. Among the 42(43.3\%) respondents that indulge in physical activity, 37(88.1\%) practice moderate form of exercise while $4(9.5 \%)$ respondents practice other forms. Also, 3(7.15\%) patients practiced daily; $10(23.8 \%)$ practiced weekly; $8(19.0 \%)$ practiced twice a week while $21(50.0 \%)$ were not certain.

The results in Table 3 showed the information on the smoking status of the respondents. Among the 97 patients interviewed; $8(8.2 \%)$ were current smokers, $11(11.3 \%)$ were past smokers while $78(80.4 \%$ ) never smoked at all. Also, Out of the $8(8.2 \%)$ patients that were current smokers; $4(50.0 \%)$

\begin{tabular}{lcc} 
Table 2: Physical activity practice of the \\
respondents \\
\hline Do you engage yourself in any form of exercise? & \\
Yes & 42 & 43.3 \\
No & 52 & 53.6 \\
Not certain & 3 & 3.1 \\
Total & 97 & 100 \\
If yes, specify & 37 & 88.1 \\
Moderate & 4 & 9.5 \\
Others & 1 & 2.4 \\
Specify & 42 & 100 \\
Total & & \\
How often do you exercise? & 3 & 7.1 \\
Daily & 10 & 23.8 \\
Weekly & 8 & 19.0 \\
Twice a week & 21 & 50.0 \\
Not certain & 42 & 100 \\
Total & & \\
\hline
\end{tabular}


smoked daily, 2(25.0\%) smoked twice a week while $2(25.0 \%)$ respondents are not certain on how often they smoke.

The results in Table 4, shown the mean body mass index

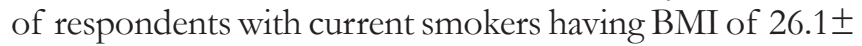
3.5 while past smokers and never smokers had 29.9 \pm 4.6 and $32.1 \pm 6.3$ respectively. Since $P<0.05$, it means that current smokers had a lower BMI compared to past and never smokers. It is statistically significant.

The results in Table 5, shown the mean systolic blood pressure of current smokers as $142.5 \pm 19.8$ while past smokers and never smokers had $131 \pm 27.1$ and $121.4 \pm 15.7$ respectively. The P-value is less than 0.05 so it is statistically significant. It shows the mean diastolic blood pressure of current smokers as 94.1 \pm 12.8 , past smokers $94.1 \pm 29.9$ and never smokers had 81.4 \pm 6.90. The $\mathrm{P}<0.05$ and also has significant relationship.

The results in Table 6, shown the mean blood glucose level of respondents with current smokers having BGL of $263.63 \pm 86.7$ while past smokers and never smokers had

\begin{tabular}{lcc} 
Table 3: Smoking status of the respondents & \\
\hline Smoking status & & \\
Current smokers & 11 & 8.3 \\
Past smokers & 78 & 11.3 \\
Never smokers & 97 & 80.4 \\
Total & & 100 \\
How often do you smoke? & 4 & \\
Daily & 2 & 50.0 \\
Twice a week & 2 & 25.0 \\
Not certain & 8 & 25.0 \\
Total &
\end{tabular}

\begin{tabular}{|c|c|c|c|}
\hline Smoking status & BMI (mean $\pm S D)$ & F-value & P-value \\
\hline Current smokers & $26.1 \pm 3.5$ & 3.973 & $0.022^{*}$ \\
\hline Past smoker & $29.9 \pm 4.6$ & & \\
\hline Never smoker & $32.1 \pm 6.3$ & & \\
\hline Total & $31.4 \pm 6.2$ & & \\
\hline
\end{tabular}

\begin{tabular}{|c|c|c|c|}
\hline Smoking status & $\begin{array}{l}\text { Blood pressure } \\
\text { (mean } \pm S D)\end{array}$ & F-value & P-value \\
\hline \multicolumn{4}{|l|}{ Systolic } \\
\hline Current smokers & $142.5 \pm 19.8$ & 6.227 & $0.003^{*}$ \\
\hline Past smoker & $131.5 \pm 27.1$ & & \\
\hline Never smoker & $121.4 \pm 15.7$ & & \\
\hline Total & $124.3 \pm 18.6$ & & \\
\hline \multicolumn{4}{|l|}{ Diastolic } \\
\hline Current smokers & $94.1 \pm 12.8$ & 8.440 & $<0.001^{*}$ \\
\hline Past smokers & $94.1 \pm 29.9$ & & \\
\hline Never smokers & $81.4 \pm 6.90$ & & \\
\hline Total & $83.9 \pm 13.0$ & & \\
\hline
\end{tabular}

169.18 \pm 94.2 and 115.55 \pm 59.4 respectively. Since $\mathrm{P}<0.05$, it means that current smokers had a higher BGL compared to past and never smokers. It is statistically significant.

\section{DISCUSSION}

Socio-Demographic Characteristics of Respondents The mean age of respondents in this study was $61.47 \pm 12.7$ years with their age range between 35 and $\geq 75$ years. Respondents between ages of 45 and 54 years were $26.8 \%$ which was the highest compared to $17.5 \%$ of the respondents that are $\geq 75$ years of age. Increase in age is associated with increase in risk of developing type 2 diabetes. According to, ${ }^{6}$ the risk of type 2 diabetes increases as one gets older especially after the age of 45 where people tend to exercise less, lose muscle mass and gain weight. There were slightly more males than females evaluated in this study. The majority of patients were between 45 and 64 years of age. The result showed in this study about age was corresponded to the study conducted by ${ }^{31}$ in University of New South Wales (UNSW) where the majority of patients were between 45 and 64 years of age. The age range for males was 18 to 90 years (mean 58.4) and for females 19 to 95 years (mean 60.5). Majority of the respondents in this study were educated. Most of the patients in this study had only attained tertiary education. This was not the case in other studies where less educated patients seemed more likely to be diabetic than other individuals with diabetes. ${ }^{32}$ This particular group of patients may not really be the target of appropriate health education as more information is needed prior to smoking. The occupational distribution among the respondents in this study presents civil servants as the highest because this research was carried out in an urban area where most dwellers were government workers with monthly income; they tend to seek medical help more compared to people from other occupational groups. The distribution of respondents according to their marital status has significant difference in married compared to single, divorced, widows and widowers. The majority of marital status with diabetes lack physical activity due to the nature of work.

\section{Physical Activity of the Respondents}

In this study, it was discovered that the practice of physical activity was the most common among patients with diabetes.

\section{Table 6: Association between blood glucose leve (BGL) and effect of smoking in type 2 diabetes}

\begin{tabular}{lccc}
\hline Smoking status & $\begin{array}{c}\text { Blood glucose } \\
\text { level (mean } \pm \text { SD) }\end{array}$ & F-value & P-value \\
\hline Current smokers & $263.63 \pm 86.7$ & 19.88 & $<0.001^{*}$ \\
Past smokers & $169.18 \pm 94.2$ & & \\
Never smokers & $115.55 \pm 59.4$ & & \\
Total & $133.85 \pm 78.2$ & & \\
\hline *Fisher exact $P$ value, level of significance $(P<0.05)$ & &
\end{tabular}


This indicates the popularity of physical activity amongst Type 2 diabetic patients. Those respondents that indulge in physical activity had a moderate practice whereas some of them that do not engage at all as the reason given by them were lack of time due to their nature of work. Therefore, a wise consideration should be employed for physical activity as a recommendation to this group of patients.

Effect of smoking on Body Mass Index (BIMI) of the Respondents

With regards to BMI and smoking, the mean was significantly higher in never smokers $(32.1 \pm 6.3)$ compared to current $(26.1 \pm 3.5)$ and past smokers $(29.9 \pm 4.6)$ respectively. Findings from this study revealed a significant relationship $(p=0.022)$ between the smoking status and BMI of the respondents. This study shows that BMI of current smokers is low compared to that of past and never smokers. The result is consistent with the findings of World Health Organization Monitoring Cardiac Disease (WHO MONICA) surveys which reported that BMI was lower in active smokers than in past and never smokers in 20 (men) and 30 (women) of the 50 population. This study is also in agreement with the sixth National Health and Nutrition Examination survey (NHANES VI) study 1990-1995 which reports that smokers weigh less than non smokers and the body leanness increases with the duration of smoking. Smoking affects body weight by increasing the metabolic rate, decreasing metabolic efficiency or decreasing caloric absorption (reduction in appetite), all of which are associated with tobacco use. The metabolic effect of smoking could explain the lower body weight found in smokers. In addition, Nicotine in tobacco increases energy expenditure and could also reduce appetite which explains why smokers have lower body weight than non smokers and why smoking cessation is frequently followed by weight gain. ${ }^{30}$

\section{Effect of smoking on Blood Glucose Level of the Respondents}

In this study there was a significant relationship between smoking status of the respondent and their blood glucose level. The mean blood glucose was low in never smokers (115.55 \pm 59.4$)$, in past smokers (169.18 \pm 94.2$)$ and high in current smokers $(263.63 \pm 86.7)$. The $\mathrm{P}<0.001$, so this study is statistically significant. This result is in agreement with the findings of ${ }^{33}$ survey which reports high blood glucose level in current smokers followed by past smokers and never smokers respectively. Increase in smoking is associated with increase in blood glucose and waist circumference. Since lower level of blood glucose leads to decreased rate of morbidity and mortality, maintaining glycaemic control is a goal for all diabetic patients. Current smokers with diabetes were more likely than past and never smokers to have higher $\mathrm{HbA}_{1 \mathrm{C}}$ levels at $45.0 \%$. It also reports a higher overall prevalence of $\mathrm{HbA}_{1 \mathrm{C}}$ values at $8.0 \%$ among current smokers. This is also in consistent with this study.

Effect of smoking on Blood Pressure of Respondents This study presents current smokers to have the highest mean blood pressure (systolic 142.5 $\pm 19.8, \mathrm{P}=0.003$ and diastolic 94.1 $\pm 12.8, \mathrm{P}=<0.001)$ compared to past and never smokers whose mean blood pressure were (systolic 131.5 $\pm 27.1, \mathrm{P}=0.003$ \& diastolic 94.1 $\pm 29.9, \mathrm{P}=<0.001$ ) and (systolic 121.4 $\pm 15.7, \mathrm{P}=0.003 \&$ diastolic $81.4 \pm 6.90$, $\mathrm{P}=<0.001)$ respectively. These results were consistent with the study by, ${ }^{19}$ which report that cigarette smoking in active smokers gradually increases blood pressure and heart rate, this raises the body's demand for oxygen. ${ }^{19}$ High blood pressure is a risk factor to many disease occurrence and posed high rate of diabetes complications.

With regards to a cross sectional survey carried out by, ${ }^{17}$ it was indicated that smoking significantly enhances the development of chronic diabetes related complications namely nephropathy and retinopathy. This is in consistent with our study. Also, a retrospective case control study of type 2 diabetic patients found that current or ex-smokers were significantly more likely to have neuropathy (nerve damage) than individuals who never smoked (64.8\% vs $42.8 \%),{ }^{19}$ this is also contradictory to this study that reports $8.3 \%$ vs $80.4 \%$ for current smokers and never smokers.

Another small study of 33 people with Type 2 diabetes who have kidney disease found that smoker's kidney function declined more rapidly than that of non-smokers, despite drug treatment, suggesting that smoking cessation could slow the progression of kidney disease in people with diabetes. This is contradictory to our findings which report that never smokers to have $80.4 \%$ of kidney damage.

\section{CONCLUSION}

In conclusion, a low proportion of Type 2 diabetic patients were smokers due to lack of proper awareness and education on the effect of smoking on diabetes, the disease is spreading widely and silently in Nigeria and other countries in world. More than half of the patients found that smoking did not give improvement rather than worsens their Type 2 diabetes. People with diabetes already have an increased risk of developing diabetic related complications and this will further elevate if they smoke.

\section{RECOMMENDATION}

Glycaemic control should be considered as the main therapeutic goal for prevention of diabetic complications 
in people that tend to smoke to prevent weight gain. Therefore, regular physical activity should be incorporated in diabetes management to prevent weight by diabetic patients. These findings indicate that more emphasis should be placed on the risk weight gain, glycemic control, blood pressure control and associated conditions among smokers. In particular, smoking cessation is frequently followed by weight gain. Smoking cessation advice should be a routine component of diabetic care. Concerns about weight gain should be addressed by health care providers.

For this study, we recommend health education on diabetes for the general population emphasizing on the dangers of smoking to health and to diabetic condition. Government and donor agencies should pay more attention on diabetes so as to eradicate this illness from our society.

\section{ACKNOWLEDGEMENT}

We wish to acknowledge the Head of Endocrinology and Diabetes Unit, Federal Medical Centre Owerri, Dr R. N Oputa. We also express our gratitude to the fieldworkers for their immense support and provision of research materials for this study.

\section{REFERENCES}

1. Diabetes United Kingdom website. Reports and Statistics: Diabetes Prevalence. 2011; Retrieved from: http://www. diabetesuk.com; April 27, 2012.

2. American Diabetes Association (ADA), Smoking and Diabetes. Diabetes Care 2010; 26(1): 89-90.

3. American Diabetes Association. Diabetes Nephropathy, Diabetes Retinopathy, Diabetes Care. Journal of American Diabetes Association 2008; 26(1): 84-100.

4. Oldroyd, J., Banerjee, $M$ and Heald A. Diabetes and ethnic minorities. Postgraduate Medical Journal, 2005; 81,486-490.

5. Diabetes Australia. Staying well with diabetes by preventing complications 2005; Retrieved from: http://www. diabetesaustralia.com. September 2, 2012.

6. Kahn AP. Diabetes; Causes, prevention and treatment. A positive and practical guide for controlling diabetes through diet, medication and exercise. $2^{\text {nd }}$ ed. New Delhi: Orient Paperbacks; 2007. p 150-300.

7. Fagard $\mathrm{RH}$ and Nilsson PM. Smoking and diabetes: the double health hazard. Primary Care Diabetes 2009; 3 (4): 2005-2009.

8. Centre for Disease Control and Prevention (CDC), Cigarette smoking and increased central adiposity. Annals Internal Medicine 2011; 111: 783-787.

9. Cooper, H. Capturing the impact of patient education for people with Type 2 diabetes. Thesis: Liverpool University. 2001.

10. Federal Ministry of Health in collaboration with WHO, EC, DFID. Standard treatment guidelines, Nigeria 2008; 90-97.

11. US Department of Health and Human Services. The health consequences of smoking. A report of the Surgeon General. Rockville, Public Health Service, Office of the Surgeon General. 2004. Retrieved from: http://www. surgeongeneral.gov. August 9, 2013.
12. World Health Organization (WHO). The incidence of type 2 diabetes mellitus in U.S: the actual causes of death in United States. Lancet 2002; 282:118-120.

13. Greenland S. Model-based estimation of relative risks and other epidemiologic measures in studies of common outcomes and in case-control studies. American Journal of Epidemiology 2004; 160(4):301-305.

14. Kumar A and Biswas UK. Smoking is associated with reduced serum paraoxonase, antioxidants and increased oxidative stress in normolipidemic acute myocardial infarct patients. Heart Asia BMJ 2011:115e119. Doi 10. 1136 / heartasia. 2011010037.4.

15. Huda A, Haider F and Hazim A. The effect of smoking on some micro vascular complications in type 2 diabetes 2010; 17: 132136.

16. Pennsylvania Medical Society. The Effect of Smoking on Type 2 Diabetes Mellitus, 2010; 3: 1-6.

17. American Lung Association. (ALA). Tobacco Policy Trend Alert. An emerging deadly trend: water pipe tobacco use. 2010. Retrieved from: http://www.lungusa2.org. January 9, 2012.

18. Al-Delaimy WK, Willett WC, Manson J E, Speizer F E and Hu FB. Smoking and mortality among women with type 2 diabetes: The Nurses' Health Study cohort. Diabetes Care 2001; 24:20432048.

19. Doll R, Peto R, Boreham J and Sutherland I. Mortality in relation to smoking: 50 years' observations on male British doctors. British Medical Journal 2004; 328: 1519-1533.

20. Windham GC, Mitchell $P$ and Anderson M. Cigarette smoking and effects on hormone function in pre-menopausal women. Environmental Health Perspective 2005; 113(10):1285-1290.

21. Collins $D$ and Lapsley $H$. The costs of tobacco, alcohol and illicit drug abuse to Australian society in 2004-2005. Canberra: Department of Health and Ageing. 2008. Retrieved from: http:// www.nationaldrugstrategy.gov. April 30, 2013.

22. U.S Department of Health and Human Services. Women and smoking. A report of the US Surgeon General. Atlanta: Centers for Disease Control and Prevention, National Center for Chronic Disease Prevention and Health Promotion, Office on Smoking and Health. 2001. Retrieved from: http://www.cdc.gov/tobacco/ data_statistics/html. August 9, 2012.

23. Bjartveit $\mathrm{K}$ and Tverdal $\mathrm{A}$. Health consequences of smoking 1-4 cigarettes per day. Tobacco Control 2005; 14:315-320.

24. British Medical Association Board of Science and Education; Tobacco Control Resource Centre. Smoking and reproductive life: The impact of smoking on sexual, reproductive and child health. 2004. Retrieved from: http://www.bma.org.uk/. September 03, 2013.

25. Millett C, Wen L M, Rissel C, Smith A, Richters J and Grulich A. Smoking and erectile dysfunction: Findings from a representative sample of Australian men. Tobacco Control 2006; 15: 136-139.

26. Stark M, Rohde K, Maher J, Pizacani B, Dent C and Bard R. The impact of clean indoor air exemptions and pre-emption policies on the prevalence of a tobacco-specific lung carcinogen among non-smoking bar and restaurant workers. American Journal of Public Health 2007; 97: 19-21.

27. California Environmental Protection Agency, Office on Environmental Health Hazard Assessment. Health effects of exposure to environmental tobacco smoke; 1997. Retrieved from: http://cancercontrol.cancer.gov. June 5, 2013.

28. National Health and Medical Research Council. Effects of passive smoking on health. Report of the NHMRC Working Party on the Effects of Passive Smoking on Health. Canberra: Australian Government Publishing Service. 1997.

29. Jane T, Qing W, Gawaine PD and Mark H. A longitudinal analysis of type 2 diabetes data from the macarthur division of general 
practice, University of new south wales(unsw) research centre for primary health care and equity. 2006. Retrieved from: http:// www.cphce.unsw.edu.au. August 5, 2013.

30. Egede LE, Ye X, Zheng D and Silverstein MD. The prevalence and pattern of complementary and alternative medicine use in individuals with diabetes. Diabetes Care 2002; 25: 324-329.

31. Houston TK, Person SD, Pletcher MJ, Liu K, Iribarren C and Kiefe $\mathrm{Cl}$. Active and passive smoking and development of glucose intolerance among young adults in a prospective cohort: CARDIA study. British Medical Journal 2006; 332: 10641069.

32. Chiolero A, Faeh D, Paccaud F and Cornuz J. Consequences of smoking for body weight, body fat distribution, and insulin. American Journal of Clinical Nutrition 2008; 87: 801-809.

33. Sargeant L, Khaw K, Bingham S, Nicholas E, Luben R, Oakes $\mathrm{S}$, Welch A and Wareham N. Cigarette smoking and glycaemia: The EPIC-Norfolk study. International Journal of Epidemiology 2001; 30:547-554.

\footnotetext{
Authors Contribution:

NJC - Concept and design, acquisition of data, analysis and interpretation of data, Manuscript preparation, Critical review and approval of manuscript; EAO - Concept and design, acquisition of data, analysis and interpretation of data; NOIS - Concept and design, acquisition of data, analysis and interpretation of data; ANA - Concept and design, acquisition of data, analysis and interpretation of data; INSD - Concept and design, acquisition of data, analysis and interpretation of data; SCI - Concept and design, acquisition of data, analysis and interpretation of data; ANA - Final proof read of manuscript and approval.
}

Source of Support: Nil, Conflict of Interest: None declared. 